\title{
Investigando con otros: la investigación en educación artística como praxis de la diferencia
}

\author{
Researching with others: research in art education \\ as praxis of difference
}

\author{
MARTA MADRID \\ Universidad de Granada. \\ martamadrid@ugr.es
}

Recibido: 18 de abril de 2012

Aprobado: 2 de julio 2012

\begin{abstract}
Resumen
Este texto reflexiona sobre las relaciones entre los actores de la investigación en educación artística como praxis de la diferencia que plantea François Collin desde el pensamiento feminista. Una propuesta para repensar las posiciones de los investigadores y las relaciones con los coactores de la investigación relacionando política, ética y estética. Comienzo situando algunas referencias en el campo de la educación artística para relacionarlos con el pensamiento de François Collin, reflexionando sobre las implicaciones que tiene en la investigación el reconocimiento de la diferencia de los otros. Por último, comento algunos aspectos de mi experiencia como investigadora en un taller de arte donde desarrollamos un proyecto audiovisual colectivo narrativo de animación stopmotion con participantes de 8 a 14 años.

Palabras clave: investigación comprometida, educación artística, praxis de la diferencia.
\end{abstract}

Madrid, M. (2013): Investigando con otros: la investigación en educación artística como praxis de la diferencia. Arte, Individuo y Sociedad, 25(2) 261-270

\begin{abstract}
Francois Collin's feminist thinking is reviewed by this article. Art education uses this ideas in order to focus the researcher as an ethic and estetic politician. These ideas are included in this audiovisual Project, which has been carried out with children and adolescents (from 8 to 14) of the ADERES (Asociación por el Desarrollo de las Relaciones Sociales) of Granada, España.
\end{abstract}

Key Words: engaged research, art education, praxis of difference.

Madrid, M. (2013): Researching with others: research in art education as praxis of difference. Arte, Individuo y Sociedad, 25(2) 261-270

Sumario: 1. Investigando en educación artística: expresión y experiencia, 2. Posiciones del investigador/a y relaciones entre los actores de la investigación, 3. Dominación y exclusión; liberación e inclusión. Una educación artística postmetafísica, 4. La investigación como creación de relaciones y narrativas significativas. Algunos fragmentos sobre mi experiencia. Referencias. 


\section{Investigando en educación artística: expresión y experiencia}

Como investigadora en educación artística, me parecen de gran interés los dos conceptos clave de los que parte Imanol Aguirre (2005) para desarrollar su visión pragmatista de una educación artística, expresión y experiencia, ambas marcadas por la contingencia. La visión pragmatista de Aguirre, inspirada por el filósofo Richard Rorty (1991), parte de la conciencia de la contingencia de la experiencia humana del mundo. Rorty habla de la contingencia como incapacidad de la filosofía para describir la realidad de forma verdadera, concluyendo que la realidad es una construcción. Siguiendo a Rorty, Bruner y Pearse, Aguirre plantea que el arte es una actividad de creación contingente de significados a través de las relaciones humanas: "el arte es un proceso social que podemos llamar producción cultural" (Pearse, 1992: 250).

Entre los paradigmas de educación artística que diferencia Aguirre, encuentro de interés el arte como saber, el arte como expresión, el arte como experiencia y el arte como lenguaje. Mientras que una educación artística que comprenda el arte como saber se encargaría de la transmisión de las destrezas técnicas en las disciplinas tradicionalmente consideradas como artísticas y sus evoluciones contemporáneas (dibujo, pintura, escultura), una educación artística expresionista antepondría el crecimiento personal y la autoexpresión a la adquisición de virtuosismo técnico -con el riesgo de proyectar el culto al individuo propio del romanticismo-. Una educación artística que comprensa el arte como experiencia, (Dewey, 2008) propone relacionar la experiencia estética cotidiana con la práctica artística, destacando que el arte se aprende mediante la práctica; desafiando la noción de que se ha de nacer con un don especial para la práctica artística. El arte como lenguaje propone la educación plástica y visual como alfabetización para la interpretación de imágenes en detrimento del aprendizaje de las destrezas artísticas. De este modo, se antepone la creación de una capacidad crítica ante los productos mediáticos a la creación de producciones contestatarias alternativas. Aguirre propone la combinación de los diferentes modelos coexistiendo entre sí el estímulo de la capacidad crítica y la práctica artística destinada al aprendizaje de técnicas expresivas, resaltando el arte como experiencia.

El propósito de Dewey de relacionar la vida y el arte tiene grandes repercusiones para la investigación en educación artística, abriendo la posibilidad de considerar las relaciones interpersonales como creación valiosa que se da en la experiencia investigadora colectiva. Dewey sitúa el hecho artístico como fenómeno relacional donde nuestra biografía se entreteje con la obra que tenemos delante; cuando enlazamos con la obra de arte lo que interpretamos con lo que somos o aspiramos a ser. Para Dewey, la posibilidad de que algo pueda ser experimentado estéticamente no reside en la cosa en sí, ni en el origen de la propia experiencia, sino en el sentido que el receptor da a su relación con el evento. Poniendo atención en las relaciones interpersonales que se crean en el grupo investigador -a través de los objetos artísticos- se abre una concepción de educación artística como creadora de vínculos interpersonales.

De esta manera, la investigación en educación artística podría tener entre sus objetivos, crear estrategias de trabajo para el desarrollo de experiencias que narrasen el proceso de aceptación de uno mismo como otro y con otros, y desarrollar la 
solidaridad ante los demás a través de la práctica artística.

Pero ¿qué posiciones tomamos como investigadores en esta práctica?

\section{Posiciones del investigador/a y relaciones entre los actores de la investigación}

Me parece de gran interés la aplicación del pensamiento de la autora feminista belga François Collin (2006) a la práctica investigadora en educación artística, a pesar de que la autora plantee su reflexión desde la filosofía y el feminismo. François Collin plantea la praxis de la diferencia como acción política en la contradicción que plantea la filosofía que enuncia la muerte del sujeto y el reclamo político del movimiento de liberación de las mujeres. Mientras que la filosofía posmoderna diagnostica la muerte del sujeto y de la autoría (Barthes, Derrida, Foucault), el movimiento feminista reclama para las mujeres convertirse sujetos autores de pleno derecho. Collin observa un desfase entre lo que ocurre en el ámbito filosófico, donde se destituye el sujeto por su carácter dominante o logofalocéntrico y la reivindicación de las mujeres que aún no han sido reconocidas como sujetos de sus propios discursos y que reivindican la obtención de un espacio público en el cual manifestarse por la palabra y por la acción. Desde esta situación contradictoria, donde la filosofía comienza a devenir mujer en su tendencia contemporánea a lo no-uno (Jacques Lacan), la diferencia y diferancia (Jacques Derrida) y el pensamiento débil (Gianni Vattimo), las mujeres feministas proceden a su masculinización adoptando posiciones fálicas de voluntarismo y poder de cambio. Desde esta reflexión crítica, la autora propone una posición híbrida donde coexisten "lo uno y lo otro": una posición conflictiva generada por una tensión fundamental donde cohabitan tanto el sujeto político que habla y actúa en el espacio público, como la experiencia de la alteridad radical. Propone la existencia en los contrarios; en la misma persona cohabitan dos versiones: "una que es la del hacer, la otra la del deshacer; una la del dominio y la otra la del desasimiento" (Collin, 2006: 32).

La autora encuentra en esta contradicción un conflicto trágico a partir del cual se hace tres preguntas fundamentales que articulan la praxis de la diferencia:

¿Cómo actuar sin acompañarse de la figura del dominio?

¿Cómo trabajar en la pasividad del dejar ser y trabajar para cambiar lo que es?

¿Cómo conciliar la afirmación de heteronimíal del sujeto, habitado por el Otro y por los otros, con su autonomía?

A partir de estos cuestionamientos, la autora afirma que el fin del Uno es el fin del Dos, y argumenta, siguiendo a Derrida, que el fin del sujeto supone un movimiento siempre recomenzado de deconstrucción que no tiene resolución final. En este sentido, el tratamiento de los hombres y las mujeres es irreductible a las categorías de los masculino y lo femenino, cuestionando el binarismo existente entre las categorías sexuales identitarias.

Para Collin, la diferencia está instruida por la dominación que se inscribe en la realidad bajo formas múltiples, irreductibles a una causa única o a un origen histórico 
determinado. Nos alerta de la confusión entre igualdad e identidad; ya que la propuesta de ser iguales supone hacernos idénticos; mientras que ser desiguales nos confronta con la realidad de ser diferentes:

"Se encuentra aqui el pensamiento de la ilustración que propone un modelo de ser humano que obedece a un modelo de hombre dominante; bajo un manto de universalismo; el extranjero sólo tiene derecho a la igualdad si imita al autóctono, la mujer sólo se vuelve plenamente humana si se vuelve hombre" (Collin, 2006:30).

Las diferencias se ponen en práctica en las relaciones humanas. No pueden decirse sino en la experiencia del diálogo y de sus conflictos, en el espacio privado y público: "La diferencia es teóricamente indecible pero se decide y redecide en toda relación" (Collin, 2006: 37). La cuestión de la diferencia sexual puede extenderse a las diferencias humanas en general y en particular, en tanto que supone aprender que no se sabe quién es el otro y nos incita a arrancar preguntas que eviten la determinación de los diferentes en el orden del saber, para hacer de la duda un acto, una praxis ética y política:

"Las diferencias se juegan en las relaciones, son un actuar entre la repetición de las sujeciones y la apertura a lo nuevo en la que ninguno/a sabe cual es su lugar, dándose la oportunidad de descubrirse y revelarse a otro, como otro". (Collin, 2006: 39).

La igualdad no puede operarse sino en el reconocimiento de la multiplicidad de los egos, de que cada individuo es ante todo relación consigo mismo, pero sin ser el único. La ética o política que reconozca el sujeto, ha de reconocer que el sujeto es muchos: "el ser en el mundo consiste en el debate desgarrador de sí mismo y el otro, residiendo la alteración en confrontarse con otros sí mismos" (Collin, 2006: 40). La diferencia no desaparece, se muta en un diferir perpetuo que Derrida denominó "diferancia", marcando su carácter móvil y activo. En la práctica investigadora, reconocer la diferencia del otro supone aceptar posiciones a negociar de forma continua entre los actores de la investigación.

\section{Dominación y exclusión; liberación e inclusión. Una educación artística postmetafísica}

Señalando en un primer momento la diferencia sexual como causa de la dominación y de la exclusión del espacio público de las mujeres como actoras; podemos solidarizarnos con otras diferencias entre los seres humanos que dan lugar a relaciones de dominación y exclusión (diferencias culturales, de nacionalidad, de poder adquisitivo, diferencias físicas y mentales, diferencias en las capacidades intelectuales y de relación social) y comprometernos con una actividad investigadora como praxis de la diferencia. Desde su pensamiento crítico, Collin nos alerta del riesgo de verse seducida por el mito de la liberación: "a fuerza de superar el dominio, los movimientos de liberación son contaminados por la posición dominante a la que hacen frente" (Collin, 2006: 32). En este sentido, la autora habla de la condena de lo político que reduce al ser humano a combatiente, con el riesgo de volverse semejante al amo, sabiendo que toda revolución tiende la cama a la dictadura; "no puede matarse al amo sino matando al 
amo que está en uno" (Collin, 2006: 33). Propone entender la liberación como idea reguladora, no como ideal utópico revestido de totalidad.

François Collin se pregunta cómo concebir una política no metafísica sin la reconciliación de sí mismo consigo mismo que encierre a los actores en la identidad colectiva y sin hacer apología de la autonomía o la autoliberación. Ella aboga por la escapada en lo político del reduccionismo de lo político, atendiendo al desfallecimiento del yo en todos nosotros, reconociendo la pluralidad y la alteridad. Para ello hemos de reconoce que el sujeto está alterado, es presa del otro, y por eso mismo es para siempre inadecuado respecto a sí mismo. El procedimiento de dominación consiste en sustraerse a esta alteración, instituyendo al otro en lugar del objeto y sustituyendo el diálogo con otro por un discurso sobre el otro. Una investigadora que reconozca la alteridad de los sujetos, ha de estar alerta para saber rechazar la posición de poder que sustituya el diálogo con otro por un discurso sobre otro. Una investigación propuesta como praxis de la diferencia requiere una actitud de escucha y aprendizaje en relación a otros, que se abre a la incertidumbre y a lo desconocido. Investigar con y no sobre otros, propone una relación en la que es necesario reconocer y aceptar las diferencias entre coinvestigadores. Supone dejar de situarse como dominante para establecer una relación basada en el diálogo y la negociación.

La pregunta por una política no metafísica me lleva a la pregunta por una educación no metafísica que permita acceder a la posición de actores de nuevas instancias hasta entonces excluidas a las personas participantes, con su poder de innovación, sin poder prever lo imprevisto del actuar. Una educación no metafísica es una educación que incluye las diferencias en el grupo o en los grupos de personas con los que trabajamos; una acción de aprendizaje que se abre a los otros cuestionándonos quienes somos y quienes podemos ser en relación unos con otros. Collin concluye que lo postmetafísico no es la muerte del sujeto sino su inscripción entre la vida y la muerte. La toma de conciencia de la alteración, del hecho de que el sujeto no es amo ni es transparente a sí mismo para sí mismo, nos lleva a comprender la existencia en la tensión entre acoger lo que es e intervenir en lo que es. Una tensión presente en la práctica artística y educativa.

La práctica investigadora en educación suele tener como objetivo intervenir para transformar un contexto humano, supone realizar una acción ética y política. La investigación acción participativa comprometida parte de la empatía con los coactores de la investigación proponiéndose una acción que cuente con las particularidades y deseos de las personas con las que se investiga y que ésta suponga una mejora en sus vidas (Stavenghagen, 2006: 83). François Collin se interesa por el término de acción política que plantea Hannah Arendt. Ella comprende el movimiento de liberación de las mujeres como un movimiento que no obedece a una doctrina predeterminada que dicte sus líneas de conducta, sino que obedece al estímulo continuo de la reflexión para iluminar la acción, para "juzgar" y "decidir" en función de la coyuntura en un debate de posiciones diversas y enfrentadas que requieren de un continuo diálogo plural. Ese movimiento, supone una praxis; una acción que no es la puesta en práctica de una teoría anterior, sino la constitución de lo que no tiene modelo, un "ir hacia lo que todavía no es"; una "iniciativa sin garantía", en el sentido aristotélico de la poiesis (Collin, 2006:13). En este sentido, la práctica política de las mujeres, la 
praxis de la diferencia puede ser también la práctica política de los educadores e investigadores comprometidos -cuando las investigaciones se basan en las preguntas anteriormente planteadas-.

La transformación del lugar de los individuos y de las relaciones sociales, políticas, económicas y simbólicas requiere una estrecha interrelación entre acción colectiva e iniciativa singular. La transformación de las estructuras condicionan la posición de cada uno/a, pero, inversamente, el cambio de las estructuras sólo es posible y sólo puede ser eficaz gracias a la iniciativa de cada uno/a. Como señala Judith Butler (2006), el sexo es preformativo; no se fabrica, se ejerce, y se ejerce bajo condiciones o límites. No nos podemos dejar seducir por la fantasía queer donde cada uno puede ser potencialmente todo autodeterminándose libremente en un sentido o en otro. Del mismo modo, el ser es preformativo, se construye en los límites del otro. La praxis de la diferencia está animada por la ética de la liberación como idea reguladora del ser/ estar en el mundo en relación a otros, cuestionándose continuamente por el significado de la liberación, siempre parcial, personal y colectiva, singular y plural. Me parece interesante recalcar el sentido parcial de esta liberación que entiendo como búsqueda de la posibilidad de la negociación, de la modulación de nuestra posición subjetiva en las relaciones de poder, como posibilidad de cuestionamiento y de situarnos y ser situados de otro modo, en relación a otros.

Para transformar el mundo común, cada compromiso particular en la manera de estar uno mismo con los demás es esencial. A Collin le interesa relacionar lo político y lo ético del mismo modo que lo hace Ana Arendt; relacionando la lucha por la liberación (política) con la posibilidad de cada uno para elaborar de una forma singular su pertenencia a un colectivo o grupo (ética). Sin duda, la práctica educativa se ocupa de la regulación de las relaciones humanas, ambivalentes y conflictivas, mediante una negociación permanente, precaria, que negocia continuamente los límites de la individuación (ética). Es también, un intento de cambiar el mundo y hacerlo un mundo mejor, por lo que se encuentra atravesada por un imaginario de dominación y progreso que comprende un conjunto de ideales y valores (política). Me parece interesante plantearse el riesgo que comprende la actitud política de aprehender cada uno en términos colectivos y no singulares ("los oprimidos" ya supone una colectivización que puede no dar lugar a preguntarse de qué forma particular está cada uno sometido a qué opresión). También me parece necesario que los educadores nos preguntemos ¿en qué mundo común deseamos convivir? Y plantear una acción ética en esta dirección. En este sentido, la cuestión ética reside en encontrar un punto de acuerdo entre receptividad y acción, entre el acoger y el cambiar, entre lo que es y lo que se querría ser o hacer que fuera.

Siguiendo el pensamiento de Levinas, Collin nos recuerda que el yo es el primer interlocutor para cada uno:

"primero ha de asumirse el deseo que lo anima; después, el yo puede buscar cómo podrá expresarse su deseo en el encuentro con otros deseos, con el deseo del otro, y elaborar momentos de acuerdo siempre frágiles y siempre renegociados" (Collin, 2006: 100). 
En ese espacio de búsqueda del deseo particular y el modo de articulación con otros, en esas relaciones donde se ha de establecer continuamente el límite de la individualidad, reside la posibilidad de ejercer una investigación en educación artística como praxis de la diferencia. Las tensiones que supone la delimitación del propio espacio, como espacio finito, forman parte de los conflictos que surgen en las aulas o talleres de arte. Esos límites de las relaciones hacen posible el respeto del espacio del otro de una manera distinta al modo de la apropiación, competitiva o envidiosa.

Siguiendo a Arendt, Collin propone una ética del diálogo plural que evita tanto el individualismo como el comunitarismo, principio fundador de lo ético (regulación de las relaciones interindividuales) y de lo político (lo que hace viable un mundo común). Un diálogo donde los espacios son cogestionados y cada uno se hacer responsable de su espacio y de las interferencias con el espacio del otro. Collin propone una praxis de la diferencia basada en la ética de los límites que busca la medida de las distancias necesarias para el respeto y la colaboración sin absorción del otro o por el otro.

\section{La investigación como creación de relaciones y narrativas significativas. Algunos fragmentos sobre mi experiencia}

En mi experiencia como investigadora he trabajado desarrollando talleres de arte en la asociación ADERES en Granada, a la que acuden chicos/as de características diversas (dificultades de relación social por motivos psicológicos, físicos, sociales, etc.), donde elaboramos un trabajo audiovisual colectivo de animación ${ }^{2}$. Comencé esta experiencia durante el curso 2009-2010 y continuo con otro taller este curso 2010-2011 junto con el animador Miguel López. Trabajamos con la frecuencia de una sesión a la semana de una hora, en el aula la asociación, durante los nueve meses del curso escolar. Somos tres coordinadores adultos (una estudiante de psicología, un artista de animación y yo) en colaboración con un grupo de seis a nueve participantes cuya edad oscila entre los 8 a los 15 años. El objetivo de la práctica es tanto la transmisión de destrezas plásticas y narrativas, como la creación de una historia que articule algo de lo particular en una elaboración colectiva, la creación de relaciones interpersonales y la adquisición de habilidades para la negociación o transformación de los conflictos en el grupo.

Lo interesante de plantear un proyecto de creación de animación, es la necesidad de negociación constante que requiere la colaboración entre los participantes para llevarlo a cabo. Tanto la fase de diseño de personajes, creación del guión, elaboración de los fondos y animación, suponen compartir espacios corporales de acción, negociar las aportaciones individuales para sumarlas en una colectiva y tomar decisiones constantemente, consensuándolas con otros. Sin una colaboración estrecha de los participantes y una toma de responsabilidad de la tarea de uno con respecto a los otros, la elaboración del proyecto no sería posible.

La duda es una constante en un proceso de creación donde yo propongo pero son los participantes los que disponen: los que se comprometen -o no- con el trabajo y la colaboración que supone con sus compañeros. Como investigadora y artista me veo situada en la tensión que se produce entre mis deseos y expectativas por un buen resultado estético y la necesidad de escucha y atención a los intereses y conflictos in- 
terpersonales del grupo, que a menudo, supone un desencuentro respecto mis deseos y expectativas.

Mi papel como investigadora/ compañera/ profesora oscila entre estas tres posiciones y mi criterio como profesora/ artista es continuamente cuestionado por el grupo:

ha de asumirse el deseo que lo anima; después, el yo puede buscar cómo podrá expMarta (a J): yo creo que no es adecuado plantear una perspectiva para la cara que se ve desde arriba y otra diferente para la torre que se ve de frente. Me resulta incómodo.

$R$ : pues yo lo comprendo perfectamente.

Marta (a J): yo dibujaría la cabeza en una esquina, así, como volviéndose...

$R$ : pero si se entiende perfectamente.

Marta: bueno, pues si tu compañero dice que se comprende perfectamente no tienes por qué hacerme caso. Yo sólo tengo una opinión, pero él tiene otra diferente igualmente válida. Tú decides.

Como coordinadora, estimo necesario dudar sobre la conveniencia o no de mis intervenciones, su intensidad y su objetivo. ¿Debo yo interceder cuando surge un enfrentamiento entre los participantes? ¿O deben resolverlo ellos? En una actitud de escucha, como investigadora, aprendo a otorgarle al grupo su capacidad de resolución.

Marta: ¿Creéis que este dibujo es tan feo como para que ella lo rompa?

$D, M, R$ y $S:$;Nooooooo!

$A:$ Sí, ese dibujo es ridículo.

Marta: ¿pero cómo puedes decir que es ridículo?

$R$ : Sí es ridículo porque es humorístico y el humor es ridículo porque nos da risa.

Otras veces, es necesario intervenir y demarcar los límites éticos de nuestras relaciones, por ejemplo, ante una amenaza de agresión. Por otro lado el no actuar, renunciar a nuestra actividad, puede funcionar como reclamo de la responsabilidad activa del otro:

Marta: a veces te enfadas antes de intentarlo. ¿Qué dificultad tienes?

L: No sé hacerlo

Marta: ¿Cómo que no? ¡Nadie sabe pintar sin aprender antes! Además, estamos haciendo manchas, todos podemos hacer manchas. Pero antes de aprender hay que tener ganas... ¿Tú tienes ganas?

L: NO. (Con cara de enfado)

M: pues entonces yo no puedo ayudarte.

Estos fragmentos de diálogos forman parte de mi diario de campo que recoge la narración de la experiencia del taller. Estos fragmentos recogen escenas de una experiencia donde he de tomar decisiones y asumir mi posición inestable como investigadora/ profesora/ compañera de taller. La cuestión de cómo saber si la práctica está siendo adecuada ha de ser respondida en función de las reacciones de los participantes y la percepción de un mismo/a. Como conclusión parcial de mi experiencia, puedo afirmar que es importante prestar atención a la percepción estética de nuestro 
cuerpo y de los cuerpos de los participantes durante nuestra práctica investigadoraeducativa: si lo sentimos excitado, acelerado, pesado y desganado o ágil, liviano o en una práctica de movimiento similar a la danza. Es necesaria una actitud de escucha de uno mismo y del grupo para gestionar emociones, actitudes, palabras y acciones. En los momentos en los que he sentido que arrastraba al grupo a una dinámica que yo había propuesto y que resultaba dificultosa, he sentido que mi cuerpo cargaba todo el peso del trabajo del grupo, y por tanto, debía aligerar la carga y dejar de liderar el trabajo para dar lugar a una dinámica más participativa. Cuando he sentido mi cuerpo ligero, danzante en un movimiento circular que buscaba desplazarse entre el trabajo de los participantes, he sentido que conseguía prestar una atención equilibrada al grupo dejando que ellos hiciesen, $\mathrm{y}$ he sentido que esa dinámica era más adecuada y agradable para los chicos/as y para mí

\section{Referencias}

Aguirre, I. (2005). Teorías y prácticas en educación artística: ideas para una revisión pragmatista de la experiencia estética. Barcelona: Octaedro.

Arendt, H. (1984). La vida del espíritu. El pensar, la voluntad y el juicio en la filosofía y en la política. Madrid: Centro de estudios Constitucionales.

- (1993) La condición humana. Barcelona: Paidós.

Blanchot, M (2002). La comunidad inconfesable. Madrid: Arena Libros.

Butler, J. (2006). Deshacer el género. Barcelona: Paidós.

Collin, F. (2006). Praxis de la diferencia. Liberación y libertad. Barcelona: Icaria editorial.

Derrida, J. (1992). Points de suspensión. París: Galilée.

Dewy, J. (2008). El arte como experiencia. Barcelona: Paidós Ibérica.

Greetz, C. (1983): El arte como sistema cultural. Barcelona: Paidós.

Hernández, F. (2000). Educación y Cultura visual. Barcelona: Octaedro.

Lacan, J (1975). Séminaire XX. Encore. París: Seluil.

Levinas, E. (1987). Totalidad e infinito. Salamanca: Sígueme.

Lyotard, J-F. (1984). La condición posmoderna. Madrid: Cátedra.

Rorty, R. (1991). Contingencia, ironía y solidaridad. Barcelona: Paidós.

Pearse, H. (1992): "Art Education Theory and Practice in a Postparadigmatic World", Studies in Art Education, 33 (4) 244-252.

Stavenghagen, R (2006). Cómo descolonizar las ciencias sociales, en Salazar M. C. (coord.): La investigación acción participativa. Inicios y desarrollos, pp (35-57), Madrid: Editorial Popular.

Vattimo, G (2002) Las aventuras de la diferencia. Barcelona: Península. 


\section{Notas}

1. Condición de la voluntad que se rige por imperativos que están fuera de ella misma.

2. El resultado de la primera experiencia dio lugar al cortometraje Amor Repentino que puede visionarse en http://proyectoaderes.blogspot.com/2010/07/amor-repentino-cortorealizado-en-el.html

\section{Agradecimientos}

Este artículo es posible gracias a la Asociación ADERES (Asociación por el Desarrollo de las Relaciones Sociales) de Granada y a la financiación del programa de Formación de Profesorado Universitario (FPU) del Estado Español. 